\title{
Pessoa com deficiência = pessoa incapaz? Um estudo acerca do estereótipo e do papel da pessoa com deficiência nas organizações
}

\author{
Disabled person = incapable person? A study on the disabled person's stereotype and role \\ in organizations
}

Vanessa Silva Perez ${ }^{1}$

\begin{abstract}
Resumo
Este artigo apresenta o estereótipo de incapacidade muitas vezes atribuído à deficiência e a visão da própria pessoa com deficiência acerca do papel que representa socialmente (THOMAS, 1966). A compreensão dos estereótipos se mostra fundamental para entender que as generalizações podem ser úteis para o cotidiano, porém, podem trazer erros graves (HILTON e HIPPEL, 1996), especificamente para os deficientes. Realizando uma análise dos estudos sobre os tipos de grupos minoritários, grande parte dos artigos trata o conceito de estereótipo como atrelado à questão racial ou de gênero, com raríssimos trabalhos relacionados à pessoa com deficiência (OTT, 2005), reforçando a importância do tema. O estudo pretende correlacionar a Teoria dos Papéis Sociais, de Jacob Moreno (1975), a essa realidade, em sua aceitação do papel de incapacidade conferido pelos estereótipos que a sociedade traz (SANDERS, 2006).
\end{abstract}

Palavras-chave: Deficiência. Incapacidade. Estereótipo.

\begin{abstract}
This paper presents the incapability stereotype often attributed to disability and the point of view of the disabled person herself with regard to the role she plays socially (THOMAS, 1966). The comprehension of stereotypes shows to be a must to understand that generalizations may be useful for everyday life, however, they can lead to serious mistakes (HILTON e HIPPEL, 1996), specifically with regard to disabled people. Performing an analysis of studies on the types of minority groups, most papers deals with the concept of stereotype as connected to the issue of race or gender, with extremely very few papers related to the disabled person (OTT, 2005), stressing the theme's importance. The study intends to correlate the Theory of Social Role, developed by Jacob Moreno (1975), to this reality, which accepts the incapability role attributed by the stereotypes that society brings (SANDERS, 2006).
\end{abstract}

Keywords: Disability. Incapability. Stereotype.

\section{Introdução}

Existem aproximadamente 24,5 milhões de brasileiros com deficiência no país, representando $14,5 \%$ da população (IBGE, 2000). Apesar do número expressivo de deficientes e do contexto da Lei de Cotas, Lei n. 8.213, de 24 de julho de 1991 (BRASIL, 1991), que tem por objetivo incluir esse público no mercado de

Artigo submetido em 28 de setembro de 2012 e aceito para publicação em 10 de dezembro de 2012.

1 Mestranda em Administração de Empresas pela Fundação Getulio Vargas/EBAPE; Graduada em Psicologia pela UFRJ. Endereço: FGV/EBAPE - Praia de Botafogo, 190 - 4 e 5o andares, Botafogo, CEP 22253-900, Rio de Janeiro-RJ, Brasil. E-mail: vanessaperez ufrj@yahoo.com.br 
trabalho, há poucos estudos voltados ao tema nas empresas brasileiras (JABBOUR, GORDONO, OLIVEIRA et al., 2011).

Considerando as dificuldades de acessibilidade encontradas no país, o ambiente organizacional não poderia ser diferente e precisa adequar-se para favorecer a inclusão desses novos profissionais (GIL, 2012). Porém, como realizar tal adaptação considerando o julgamento das organizações acerca da pessoa com deficiência, já que a esta se atribui uma avaliação negativa desde a antiguidade? (BENVENHO e GIMENES, 2010).

Embora a Lei de Cotas esteja sendo executada de forma veemente, a dificuldade das organizações para perceber a pessoa com deficiência como força produtiva e não somente como um cumprimento legal tem sido um grande empecilho na inserção adequada desse profissional. As empresas se utilizam de subterfúgios para a contratação, como a inclusão de pessoas com deficiências leves, excluindo os deficientes sensoriais cegos e surdos, pois, dessa forma não precisam fazer uso de recursos específicos para contratação (IBDD, 2008). Ao longo deste artigo será apresentado o conceito de estereótipo que a população tem sobre a deficiência e a visão da própria pessoa com deficiência acerca do papel que representa socialmente (THOMAS, 1966). A compreensão dos estereótipos se mostra fundamental para entender que as generalizações são úteis para o cotidiano, porém, podem trazer erros graves (HILTON e HIPPEL, 1996), especificamente para os deficientes.

Uma forte justificativa para maior aprofundamento do tema seria a relevância do tema, dados os inúmeros pesquisadores brasileiros que tratam da pessoa com deficiência, conforme demonstrado em artigo desenvolvido por Brunstein e Serrano (2008). Além disso, em função de pesquisas anteriores, há uma necessidade premente de identificar a visão que pode estar envolvida quando falamos de pessoas com deficiência (IRIGARAY e VERGARA, 2011).

Detalhando os tipos de grupos minoritários, grande parte dos estudos trata o conceito de estereótipo como atrelado à questão racial ou de gênero, com raríssimos artigos relacionados à pessoa com deficiência (OTT, 2005), reforçando a importância do tema. A proposta que se segue neste artigo é atrelar à realidade da pessoa com deficiência à Teoria dos Papéis Sociais, de Jacob Moreno (1975), em sua aceitação do papel de incapacidade conferido pelos estereótipos que a sociedade traz (SANDERS, 2006).

\section{Referencial Teórico}

\section{Estereótipo}

Para iniciar a explanação sobre o conceito de estereótipo, faz-se necessário expor sua relação com o preconceito, termo mais difundido na sociedade. Este vem de longa data em nosso processo histórico, tendo exemplos desde a antiguidade romana e sendo ainda bastante presente nos dias atuais (RODRIGUES, ASSMAR e JABLONSKI, 1999; STANGOR e LANGE, 1994).

A ideia do preconceito como construção científica é produzida desde os anos 1920, inicialmente mais influenciada pela questão racial (DUCKITT, 1992). Gordon Allport, um dos pioneiros no estudo sobre o tema organizou, em 1954, uma massa de pesquisa para produzir um estudo de referência sobre as raízes e a natureza do preconceito (KATZ, 1991). Muitas explicações socioculturais têm sido utilizadas pelos sociólogos para explicar a origem do preconceito, como fatores institucionais e históricos, incluindo segregação, escravidão e estratificação social, mas ainda não se mostram satisfatórias para explicar tais questões (STEPHAN e STEPHAN, 1996).

A natureza do preconceito definiu o campo das relações intergrupais para os psicólogos sociais como o estudo desse tema e seus efeitos sobre as interações do grupo. Ele organizou o conhecimento existente sobre os determinantes do grupo, da sociedade e da personalidade de aquisição de preconceito e persistência, tratando esse fenômeno como um caso especial de funcionamento cognitivo normal (KATZ, 1991). 
E é a partir do preconceito que é possível trazer à tona a ideia de estereótipo, sendo este a base cognitiva do preconceito, segundo psicólogos sociais contemporâneos (GAUNT, 2011; RODRIGUES, ASSMAR e JABLONSKI, 1999). A palavra tem origem grega, stereos e túpos, que significam, respectivamente, "rígido" e "traço" (RODRIGUES, ASSMAR e JABLONSKI, 1999).

Atualmente, temos um número bastante significativo de definições sobre o termo, além de muitos estudos sobre o tema (RODRIGUES, ASSMAR e JABLONSKI, 1999; STANGOR e LANGE, 1994).

Para capturar a ideia de um estereótipo, Walter Lippmann, em sua obra de 1922, desenvolveu o conceito muito antes de a importância psicológica dos estereótipos ser vista pelos grandes centros de referência da época. Criou a ideia de estereótipo como "fotos em nossas cabeças" para ilustrar o que caracterizou como uma representação interna mental de grupos sociais, em contraste com a sua realidade externa (BANAJI e BHASKAR, 2000).

O estereótipo é uma forma de simplificar nossa visão de mundo, poupando tempo e energia ao realizar determinadas generalizações. A categorização pode ser considerada uma das funções mais básicas dos seres vivos. Da mesma forma que categorizamos os objetos como carros, xícaras, roupas (MERVIS e ROSCH, 1981), o mundo social também passa por esse tipo de processo (STANGOR e LANGE, 1994). Funciona como uma lei do menor esforço (MACRAE e BODENHAUSEN, 2001). O estereótipo refere-se a crenças, conhecimentos e expectativas da vida social (BANAJI e BHASKAR, 2000).

A visão trabalhada por Gordon Willard Allport e Henri Tajfel é de que os estereótipos são inerentes ao ato de categorização social e constituem a base da visão moderna. São subprodutos de processos básicos de percepção e categorização, aprendizagem e memória. Essa visão cognitiva vem dominando o campo desde o início dos anos 1980 (BANAJI e BHASKAR, 2000).

De forma geral, o que existe de comum nas definições de estereótipo é a "crença compartilhada acerca de atributos - traços de personalidade ou comportamentos - de grupos de pessoas" (RODRIGUES, ASSMAR e JABLONSKI, 1999, p. 150).

Por outro lado, é importante salientar que o conceito de estereótipo possui uma função importante na simplificação de mundo, na tentativa de prever e compreender o comportamento humano (PRATTO e BARGH, 1991).

Apesar da utilização do estereótipo como facilitador do cotidiano das pessoas, há impactos negativos que essa visão pode trazer, levando a generalizações incorretas sobre o indivíduo, produzindo injustiças e gerando julgamentos enviesados (HILTON e HIPPEL, 1996; RODRIGUES, ASSMAR e JABLONSKI, 1999).

Em função da ambivalência do conceito de estereótipo, torna-se relevante levantar até que ponto é possível trabalhar de forma harmônica, considerando esse conceito um facilitador cognitivo, porém, sempre como uma possibilidade de questionar as primeiras impressões que possam evitar o processo discriminatório.

Nas últimas décadas, os aspectos conscientes e inconscientes do estereótipo vêm sendo

bastante discutidos em pesquisa (BANAJI e BHASKAR, 2000). Estudos anteriores apresentam uma distinção entre esses dois aspectos, considerando a ativação automática e a ativação controlada (DEVINE, 1989). A ativação automática é um processo que ocorre em grande parte de forma involuntária, não intencional e sem esforço. Geralmente, são crenças bastante propagadas culturalmente. Por outro lado, a ativação controlada poderia ser considerada a possibilidade de reavaliar de forma consciente e intencional a primeira impressão percebida, reduzindo a possibilidade de atuar de forma preconceituosa (DEVINE, 1989; MACRAE e BODENHAUSEN, 2001). Segundo Sternberg (2000), além do simples controle consciente, há uma exigência forte em seu processo. Este é realizado em série, de forma sequencial, e consome um tempo maior de execução, se comparado ao processo de ativação automática. Há uma série de autores que 
pesquisam as possibilidades de reduzir o efeito da ativação automática (RODRIGUES, ASSMAR e JABLONSKI, 1999). Muitos processos de ativação controlada podem tornar-se automáticos, dependendo do esforço de cada pessoa em controlar tais pensamentos (STERNBERG, 2000).

As últimas três décadas foram significativas em descobertas experimentais, em especial sobre o papel da consciência no pensamento e o sentimento sobre os grupos minoritários (BANAJI e BHASKAR, 2000).

Detalhando os tipos de grupos minoritários, grande parte dos estudos trata o conceito de estereótipo como atrelado à questão racial ou de gênero, com raríssimos artigos relacionados à pessoa com deficiência (OTT, 2005).

Levando em consideração a situação da pessoa com deficiência e o estereótipo presente em sua relação com o trabalho, a dificuldade é concebida em função das suas limitações orgânicas, e, com isso, as medidas de inserção são baseadas mais na natureza da deficiência do que propriamente em suas reais potencialidades e necessidades. Sendo assim, há grande dificuldade em identificar potencial para o trabalho na pessoa com deficiência pelas organizações (TANAKA e MANZINI, 2005). Tais estereótipos se desenvolvem através da exposição repetida a estímulos que sempre retratam pessoas com deficiência como incapazes (SANDERS, 2006). Considerando tais referências, é possível estabelecer a primeira proposição:

Proposição 1 - As generalizações trazidas pelos estereótipos facilitam nossa percepção de mundo, porém, considerando o estereótipo de incapacidade da pessoa com deficiência, esse tipo de percepção pode dificultar sua inserção no mercado de trabalho e seu desenvolvimento profissional na organização.

\section{Papel social da deficiência}

Para compreender melhor como os estereótipos podem vir a influenciar de forma negativa a percepção da própria pessoa com deficiência acerca de sua capacidade laborativa, será apresentada neste artigo uma breve introdução da Teoria dos Papéis Sociais atrelada ao deficiente, que assume o papel estabelecido pela sociedade e sente-se como se estivesse burlando regras quando age de forma diferente do "esperado" (THOMAS, 1966). Apresentando a teoria criada por Jacob Moreno, o papel é:

[...] uma unidade de experiência sintética em que se fundiram elementos privados, sociais e culturais. Cada papel aparece como resultado de duas classes de fatores: seus denominadores coletivos e suas diferenciações individuais (MORENO, 1975, p. 238).

Como afirmam Kahn e Antonucci (1979 apud SILVA e GÜNTHER, 2000), os papéis sociais são influenciados pelo que se espera de uma pessoa e pelo que a própria pessoa espera de si mesma, confirmando uma das construções expostas por Jacob Moreno.

Outra conceituação importante trata da relação entre os papéis, na qual:

[...] todo e qualquer indivíduo, assim como é foco de numerosas atrações e repulsões, também é foco de numerosos papéis que estão relacionados com os papéis de outros indivíduos (MORENO, 1975, p. 402).

Considerando essa afirmação, existem inúmeros papéis desempenhados simultaneamente e interligados a outras pessoas com ou sem deficiência. Thomas (1966) expõe como a deficiência pode afetar os demais papéis que o deficiente representa em sua vida, como, por exemplo, o de pai, esposo e provedor do sustento familiar, podendo reduzir o nível de desempenho nessas atuações. Dessa maneira, sua identidade pessoal pode ficar comprometida. 
Ao exercer seus inúmeros papéis, como as demais pessoas, a pessoa com deficiência precisa justificar constantemente como fará isso, já que a singularidade de sua condição o mantém sob um constante fardo de explicação em relação ao modo como pode conseguir exercer determinadas atividades, além de como adquiriu a deficiência e como sua construção de vida pessoal é realizada em função da deficiência (THOMAS, 1966). Considerando uma frase de Moreno (1975, p. 25), de que "não são os papéis que emergem do eu, senão é o eu que pode emergir dos papéis", é possível elaborar a proposição a seguir.

Proposição 2A - A pessoa com deficiência possui todos os papéis de sua vida em torno da deficiência, e não em função de sua construção de indivíduo.

\section{Figura 1}

\section{Proposta ao Diagrama de Papéis de Moreno para a Pessoa com Deficiência}

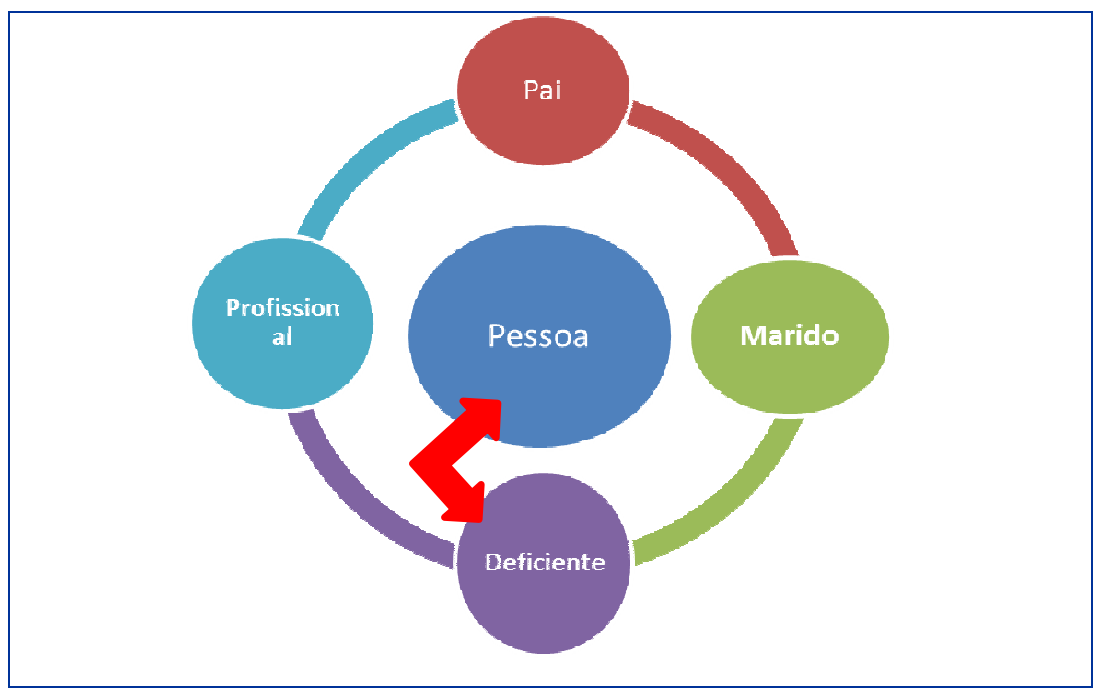

Fonte: Elaborado pela autora.

Analisando a pessoa com deficiência congênita, é possível verificar que algumas construções de papel relacionadas à incapacidade surgem na infância, sendo vítimas de uma superproteção, além do esperado para uma criança sem as mesmas características. Pais e mães não permitem que seus filhos fiquem longe deles e que possam participar de interações com outras crianças, deficientes ou não. Os filhos acabam não tendo opção de participar de eventos sociais, mesmo quando adolescentes, e, muitas vezes, sequer conseguem escolher suas próprias roupas e exercer algum tipo de autonomia. Esse tipo de superproteção também pode ser construído quando a deficiência é adquirida ao longo da vida, gerando impactos similares na vida adulta do sujeito, que regride em suas capacidades (SANDERS, 2006).

Ao longo da vida, os indivíduos, de forma geral, têm a possibilidade de vivenciar os papéis de forma distinta. Moreno (1975) apresenta as três possibilidades para o indivíduo:

- Tomada ou aceitação do papel: aceita um papel inteiramente constituído que não proporciona ao sujeito a possibilidade de construção.

- Desempenho do papel: tolera certo grau de liberdade.

- Criação do papel: deixa uma ampla margem à iniciativa do ator.

No que se refere à pessoa com deficiência, qual destas seria a mais comumente utilizada? 
Em pesquisa apresentada por Sanders (2006), foram estudados os fatores relevantes que poderiam impactar a escolha de carreira de estudantes com deficiência. Os mais significativos foram: a gravidade da deficiência; a quantidade de tempo gasto em aulas de reforço; pais e professores excessivamente protetores, que veem os alunos com baixa expectativa de desempenho; e o medo de fracassar. Desses quatro itens, o excesso de proteção e as baixas expectativas sobre o desempenho são os que possuem grandes consequências negativas para esse grupo.

É possível perceber que essas construções são externas ao indivíduo e pouco se relacionam ao nível de dificuldade que a deficiência pode causar, mas estão diretamente ligadas ao estereótipo trazido dos pais e professores para essas crianças e jovens com deficiência.

Proposição 2B - A visão estereotipada do deficiente influencia diretamente a aceitação do papel de incapacidade pela própria pessoa com deficiência. Com isso, há um processo cíclico de avaliações negativas de sua capacidade laborativa nas organizações, tanto por esse público quanto pelos demais funcionários.

\section{A questão da deficiência}

Uma das definições dadas para deficiência pela Americans with Disabilities Act (ADA) expõe ser "um limitador físico ou mental que dificulta a realização de uma ou mais atividades principais da vida" (TAUB e FANFLIK, 2000).

Analisando a produção científica norte-americana, é possível perceber que o conceito de deficiência mostrase mais amplo do que temos definido atualmente no Brasil para a inserção no mercado de trabalho, incluindo as doenças crônicas, as doenças mentais (psiquiátricas), obesidade, aids etc., apresentando a perspectiva médica também nesse contexto (HABER e SMITH, 1971; HABER, 1973; JENKINS, 1991; BAGENSTOS, 2000).

Ao considerar a Lei de Cotas no Brasil, constata-se a existência de uma delimitação das deficiências, definidas pelo Ministério do Trabalho como "toda perda ou anormalidade de uma estrutura ou função psicológica, fisiológica ou anatômica que gere incapacidade para o desempenho de atividade, dentro do padrão considerado normal para o ser humano" (GIL, 2012). De acordo com o Decreto n. 3.298 (BRASIL, 1999b), é considerada pessoa com deficiência a que se enquadra nas categorias apresentadas no Quadro 1.

\section{Quadro 1}

Tipos de deficiência contempladas na Lei de Cotas

\section{Deficiência física}

Exceto as deformidades estéticas e as que não produzam dificuldades para o desempenho de funções.

\section{Deficiência auditiva}

Perda parcial ou total das possibilidades auditivas sonoras nos dois ouvidos.

\section{Deficiência visual}

Acuidade visual igual ou menor que 20/200 no melhor olho, após a melhor correção ou campo visual inferior a 20 (Tabela de Snellen) ou ocorrência simultânea dessas situações. 


\section{Deficiência intelectual}

Funcionamento intelectual significativamente inferior à média, gerando limitações associadas a duas ou mais áreas de habilidades adaptativas.

\section{Deficiência múltipla}

Associação de duas ou mais deficiências.

Fonte: Brasil (1999).

Levantando a definição da ADA, que vem se aprimorando no trabalho de aprofundamento da questão discriminatória, há uma complementação importante sobre o conceito:

Deficiência é uma condição em que as pessoas, por causa do presente ou do passado, são vistas como fora da norma para as instituições da sociedade em que são projetadas e, portanto, possuem menor oportunidade de participar de áreas importantes da vida pública e privada (BAGENSTOS, 2000, p. 420).

Mesmo que as pessoas com deficiência possam ter situações de ordem médica muito diferentes entre si e bastante agravadas em alguns casos, o que fica notório no status socialmente atribuído ao grupo, de forma geral, tende a resultar em desvantagem sistemática e privação de oportunidade (BAGENSTOS, 2000).

A exclusão é literalmente construída em nosso ambiente físico e social. Grande parte da sociedade é projetada sem levar em conta as necessidades das pessoas com deficiência (BAGENSTOS, 2000). A relação com a empregabilidade tem sido subestimada, tendo preocupação com uma política assistencialista e desconsiderando a capacidade laborativa (HABER, 1973).

Com isso, a dificuldade desse grupo para construir uma vida acadêmica e, por consequência, uma atividade profissional está presente em seu cotidiano. Tais questões podem ser corroboradas considerando as altas taxas de desemprego e pobreza dessas minorias nos Estados Unidos, correlacionadas à falta de formação educacional e profissional de deficientes (TAUB e FANFLIK, 2000).

Estes passam diariamente por situações nas quais suas necessidades não são avaliadas e, de fato, sequer conhecidas pela grande maioria das pessoas, que ainda continuam em uma perspectiva voltada para a "compaixão" sem conhecer as reais necessidades da pessoa com deficiência a ser auxiliada. Algumas atitudes que chegam a ser irracionais são cometidas com essas pessoas. Há um exagero nos efeitos limitantes da deficiência (BAGENSTOS, 2000; DINIZ, 2007).

Um exemplo clássico na literatura (THOMAS, 1966; TAUB e FANFLIK, 2000) é o caso do deficiente visual, que é tratado como surdo quando está na companhia de outras pessoas "videntes". Nenhuma pergunta é feita diretamente a ele, mas, sempre ao acompanhante. Quando está sozinho, parado em algum lugar, há grandes chances de o cego ser conduzido a atravessar a rua, sem ter dito sequer uma palavra.

Vendo a questão sob a perspectiva da Teoria dos Papéis Sociais, é estranho pensar que a pessoa com deficiência precisa justificar constantemente sua existência. Os demais papéis a ser exercidos, como pai/mãe, marido/esposa, profissional estão comprometidos, já que é preciso informar que o cego pode ele próprio responder uma pergunta e tomar decisões sem a intervenção de terceiros. O desconhecimento de que o 
deficiente pode viver os mesmos papéis que os demais membros da sociedade geram complicações em seu cotidiano, como apresentado no exemplo anterior (THOMAS, 1966; TAUB e FANFLIK, 2000).

Considerando tais desvalorizações, o estereótipo e a estigmatização que essas minorias sofrem (BAGENSTOS, 2000; TAUB e FANFLIK, 2000), é grande o desafio de considerá-la uma categoria profissionalmente produtiva, verificando-se tamanhos empecilhos sociais.

Outra questão importante a ser revista é a perspectiva apresentada pelo conceito de deficiência ao longo dos tempos, que traz a responsabilidade do problema para a pessoa com deficiência e não para a sociedade.

Novas definições vêm sendo trabalhadas para abranger a questão da sociedade nesse posicionamento, como mostra DINIZ (2007, p. 9), definindo que "deficiência é um conceito complexo em que se reconhece o corpo com lesão, mas que também denuncia a estrutura social que oprime a pessoa deficiente". Outra definição da mesma autora bastante representativa na responsabilização da sociedade na inserção do deficiente é a "desvantagem ou restrição de atividade, provocada pela organização social contemporânea, que pouco ou nada considera aqueles com lesões físicas e os exclui das principais atividades da vida social" (DINIZ, 2007, p. 17).

O Decreto Federal n. 6.949 (BRASIL, 2009a), que promulga a Convenção Internacional sobre os Direitos das Pessoas com Deficiência, apresenta uma definição importante e mais alinhada ao momento histórico em que vivemos, em uma perspectiva voltada para as minorias e menos envolvida com a ordem médica:

[...] pessoas com deficiência são aquelas que têm impedimentos de longo prazo de natureza física, mental, intelectual ou sensorial, os quais, em interação com diversas barreiras, podem obstruir sua participação plena e efetiva na sociedade em igualdades de condições com as demais pessoas.

Essa nova forma de trazer a questão da pessoa com deficiência aparenta uma evolução no cenário brasileiro, porém, precisa ser verificada na prática. De fato, os profissionais com deficiência não têm sido avaliados como capazes para exercer qualquer função em uma organização, mas, sim, vistos como incapacitados.

Um termo que denota maior adequação seria impossibilitado, já que nossa estrutura atual não favorece o desenvolvimento pleno do sujeito com deficiência, considerando suas peculiaridades.

Em estudo apresentado por Czajka e DeNisi (1988), funcionários com deficiência são percebidos de forma menos favorável que os demais profissionais, vistos como possuindo diferentes traços de personalidade, características morais e atitudes sociais.

A partir dessas considerações, apresenta-se a última proposição sobre o tema.

Proposição 3 - A visão do problema da inserção e do desenvolvimento profissional da pessoa com deficiência ainda é vista como responsabilidade do possuidor da deficiência, e não de uma dificuldade da sociedade em absorvê-lo.

Em uma recente pesquisa, foram realizados estudos de caso em 15 organizações brasileiras de grande porte sobre a questão da diversidade, tratando mais propriamente das questões étnicas, culturais e sobre a deficiência (JABBOUR, GORDONO, OLIVEIRA et al., 2011). No que concerne à pessoa com deficiência, alguns dados importantes foram encontrados: como as pessoas com deficiência, muitas vezes, vêm de origem humilde e, com isso, falta acesso à educação, sendo impedidas pelo despreparo das escolas e da dificuldade de acesso aos transportes públicos, há pouca possibilidade de desenvolvimento de carreira. Por essa razão, muitas organizações criam cargos mais operacionais ou sem funções pré-estabelecidas para cumprir a cota, já 
que não se consegue avaliar as competências necessárias para cargos mais relevantes (JABBOUR, GORDONO, OLIVEIRA et al., 2011).

Algumas expuseram ter como meta contratar e favorecer o desenvolvimento de pessoas com deficiência, porém, buscam profissionais prontos para ingressar, sem que haja qualquer tipo de investimento.

Trainees e estagiários são fortes exemplos de investimento, sendo vistos como potenciais para a organização, tendo uma possibilidade de ascensão futura significativa. É notório que as pessoas com deficiência não são tratadas como potenciais pela empresa, mas, sim, como uma obrigação legal; a elas não são oferecidas condições reais de ser desenvolvidas.

Há muita exposição sobre mecanismos de entrada desses profissionais na empresa, porém, pouco se expõe sobre sua permanência na organização e como sua trilha de carreira é traçada. Atualmente, há uma preocupação bastante reduzida sobre o plano de carreira para a pessoa com deficiência.

Não existem muitos estudos sobre a questão no meio acadêmico. Um deles apresenta uma visão bastante conflituosa sobre o desempenho da pessoa com deficiência: o profissional pode ser visto como menos capaz e, em alguns momentos, quando supera a expectativa como outro trabalhador qualquer, é visto como excepcionalmente capaz (CZAJKA e DENISI, 1988). Considerando a análise realizada ao longo do estudo sobre estereótipos e papéis, é questionável se, de fato, a avaliação de desempenho formal da pessoa com deficiência é realizada de maneira imparcial, como os demais funcionários.

\section{Considerações Finais}

Como analisado neste artigo, há uma grande demanda para aprofundar os estudos em torno das pessoas com deficiência, especialmente em sua dificuldade de inclusão no mercado de trabalho. A partir das implicações teóricas apresentadas, será relevante trabalhar tais proposições através de pesquisas de campo, tanto nas empresas para identificar se a inclusão realmente ocorre e como isso acontece. Entrevistas e relatos de vida dos deficientes podem vir a corroborar a Teoria dos Papéis Sociais.

Pesquisas que visem a contemplar se a aceitação do papel que a pessoa com deficiência apresentava no estudo realizado por Edwin Thomas (1966) podem ser relevantes, já que o conteúdo apresentado neste artigo é revelador, porém, bastante antigo. Evidências práticas trazem essa contribuição, porém, desde então, pouco se construiu na esfera das contribuições teóricas.

É sempre importante reforçar que a Lei de Cotas vem para saldar uma dívida social com as pessoas com deficiência, porém, sozinha, em nada poderá contribuir para a mudança da visão das pessoas ditas "normais" e das organizações sobre a capacidade laborativa dos deficientes.

Ao governo cabe estruturar ações de acessibilidade e de ensino a essas pessoas, que dificilmente conseguem finalizar os estudos sem grandes empecilhos, seja pelas instituições de ensino que não conseguem se adequar a essa diversidade de públicos, seja pela impossibilidade que as estruturas físicas impõem a pessoa com deficiência. Estudos que contemplem o desenvolvimento educacional, analisando as possíveis problemáticas na forma como as escolas e universidades tratam a questão da deficiência em seus recursos didáticos e o quanto estes contribuem (ou não) para que os que possuem deficiência concorram em igualdade de condições no mercado. 


\section{Referências}

BAGENSTOS, S. R. Subordination, stigma, and “disability”. Virginia Law Review, v. 86, p. 397-534, 2000.

BANAJI, M. R.; BHASKAR, R. Implicit stereotypes and memory: the bounded rationality of social beliefs. In: SCHACTER, D. L.; SCARRY, E. (Ed.). Memory, Brain, and Belief. Cambridge: Harvard University Press, 2000. p. $139-175$.

BENVENHO, S. H.; GIMENES, A. M. A inclusão do deficiente no mercado de trabalho. 2010. Disponível em: <http://www.inesul.edu.br/revista/arquivos/arq-idvol_12_1295382099>. Acesso em: 5 ago. 2012.

BRASIL. Lei n. 8.213, de 24 de julho de 1991. Dispõe sobre os Planos de Benefícios da Previdência Social, e dá outras providências. Diário Oficial da União, 26 jul. 1991. Disponível em: <http://www.planalto.gov.br/ccivil_03/leis/L8213cons.htm>. Acesso em: 13 fev. 2012.

Decreto n. 6.949, de 25 de agosto de 2009. Promulga a Convenção Internacional sobre os Direitos das Pessoas com Deficiência e seu Protocolo Facultativo, assinados em Nova York, em 30 de março de 2007. Diário Oficial da União, 26 ago. 1999a. Disponível em: <https://www.planalto.gov.br/ccivil_03/_ato20072010/2009/decreto/d6949.htm>. Acesso em: 13 fev. 2012.

Decreto n. 3.298, de 20 de dezembro de 1999. Regulamenta a Lei n. 7.853, de 24 de outubro de 1989, dispõe sobre a Política Nacional para a Integração da Pessoa Portadora de Deficiência, consolida as normas de proteção, e dá outras providências. Diário Oficial da União, 21 dez. 1999b. Disponível em: <http://www.planalto.gov.br/ccivil_03/decreto/d3298.htm>. Acesso em: 13 fev. 2012.

BRUNSTEIN, J.; SERRANO, C. A. Vozes da diversidade: um estudo sobre as experiências de inclusão de gestores e PcDs em cinco empresas paulistas. Cadernos EBAPE.BR, v. 6, n. 3, p. 1-27, 2008.

CZAJKA, J. M.; DENISI, A. S. Effects of emotional disability and clear performance standards on performance ratings. Academy of Management Journal, v. 31, n. 2, p. 394-404, 1988.

DEVINE, P. G. Stereotypes and prejudice: their automatic and controlled components. Journal of Personality and Social Psychology, v. 56, n. 1, p. 5-18, 1989.

DINIZ, D. O que é deficiência? São Paulo: Brasiliense, 2007.

DUCKITT, J. Psychology and prejudice: a historical analysis and integrative framework. American Psychologist, v. 47, n. 10, p. 1182-1193, 1992.

GAUNT, R. Effects of intergroup conflict and social contact on prejudice: the mediating role of stereotypes and evaluations. Journal of Applied Social Psychology, v. 41, n. 6, p. 1340-1355, 2011.

GIL, M. O que as empresas podem fazer pela inclusão das pessoas com deficiência. Disponível em: <http://www.ethos.org.br/_uniethos/documents/manual_pessoas_deficientes.pdf>. Acesso em: 13 fev. 2012.

HABER, L. D. Social planning for disability. The Journal of Human Resources, v. 8, p. 33-55, 1973.

.; SMITH, R. T. Disability and deviance: normative adaptations of role behavior. American Sociological Review, v. 36, n. 1, p. 87-97, 1971.

HILTON, J. L.; HIPPEL, W. V. Stereotypes. Annual Review of Psychology, v. 47, p. 237-271, 1996.

INSTITUTO BRASILEIRO DOS DIREITOS DA PESSOA COM DEFICIÊNCIA - IBDD. Inclusão social da pessoa com deficiência: medidas que fazem a diferença. Rio de Janeiro: IBDD, 2008. 
INSTITUTO BRASILEIRO DE GEOGRAFIA E ESTATÍSTICA IBGE. Censo 2000: população residente por tipo de deficiência. 2000. Disponível em: 〈http://www1ibge.gov.br/home/estatistica/populacao/censo2000>. Acesso em: 13 fev. 2012.

IRIGARAY, H. A. R.; VERGARA, S. C. O tempo como dimensão de pesquisa sobre uma política de diversidade e relações de trabalho. Cadernos EBAPE.BR, v. 9, n. 4, p. 1085-1098, 2011.

JABBOUR, C. J. C. et al. Diversity management: challenges, benefits, and the role of human resource management in Brazilian organizations. Equality Diversity and Inclusion: An International Journal, v. 30, n. 1, p. 58-74, 2011.

JENKINS, R. Disability and social stratification. British Journal of Sociology, v. 42, n. 4, p. 557-580, 1991.

KATZ, I. Gordon Allport’s “The nature of prejudice”. Political Psychology, v. 12, n. 1, p. 125-157, 1991.

MACRAE, C. N.; BODENHAUSEN, G. V. Social cognition: thinking categorically about others. Annual Review of Psychology, v. 51, n. 1, p. 93-120, 2000.

. ; BODENHAUSEN, G. V. Social cognition: categorical person perception. British Journal of Psychology, v. 92, p. 239-255, 2001.

MERVIS, C. B.; ROSCH, E. Categorization of natural objects. Annual Review of Psychology, v. 32, n. 1, p. 89-115, 1981.

MORENO, J. L. Psicodrama. São Paulo: Cultrix, 1975.

OTT, K. Disability and the practice of public history: an introduction. The Public Historian, v. 27, n. 2, p. 11-24, 2005.

PRATTO, F.; BARGH, J. A. Stereotyping based on apparently individuating information: trait and global components of sex stereotypes under attention overload. Journal of Experimental Social Psychology, v. 27, n. 1, p. 26-47, 1991.

RODRIGUES, A.; ASSMAR, E. M. L.; JABLONSKI, B. Psicologia social. Petrópolis, RJ: Vozes, 1999.

SANDERS, K. Y. Overprotection and lowered expectations of persons with disabilities: the unforeseen consequences. Work Reading Mass, v. 27, n. 2, p. 181-188, 2006.

SILVA, I. R.; GÜNTHER, I. A. Papéis sociais e envelhecimento em uma perspectiva de curso de vida. Psicologia: Teoria e Pesquisa, v. 16, n. 1, p. 31-40, 2000.

STANGOR, C.; LANGE, J. Mental representations of social groups: advances in understanding stereotypes and stereotyping. In: ZANNA, M. P. (Ed.). Advances in experimental social psychology, v. 26, p. 357-416, 1994.

STEPHAN, W. G.; STEPHAN, C. W. Predicting prejudice. International Journal of Intercultural Relations, v. 20, p. 409-426, 1996.

STERnBERG, R. J. Cognitive psychology. Psychological Review, v. 2, n. 2, p. 567, 2000.

TANAKA, E. D. O.; MANZINI, E. J. O que os empregadores pensam sobre o trabalho da pessoa com deficiência? Revista Brasileira de Educação Especial, v. 11, n. 2, p. 273-294, 2005.

TAUB, D. E.; FANFLIK, P. L. The inclusion of disability in introductory sociology textbooks. Teaching Sociology, v. 28, n. 1, p. 12, 2000.

THOMAS, E. Problems of disability from the perspective of role theory. Journal of Health and Human Behavior, v. 7, n. 1, p. 2-14, 1966. 